\title{
Filum terminale lipomas: imaging prevalence, natural history, and conus position
}

\author{
Clinical article
}

\author{
Michael J. Cools, M.D., ${ }^{1}$ Wajd N. Al-Holou, M.D., ${ }^{1}$ William R. Stetler JR., M.D., ${ }^{1}$ \\ Thomas J. Wilson, M.D., ${ }^{1}$ Karin M. Muraszko, M.D., ${ }^{1}$ Mohannad Ibrahim, M.D., ${ }^{2}$ \\ Frank La Marca, M.D., ${ }^{1}$ Hugh J. L. Garton, M.D., M.H.Sc., ${ }^{1}$ \\ ANd CoRmac O. MAher, M.D. ${ }^{1}$
}

Departments of ${ }^{1}$ Neurosurgery and ${ }^{2}$ Radiology, University of Michigan, Ann Arbor, Michigan

\begin{abstract}
Object. Filum terminale lipomas (FTLs) are being identified with increasing frequency due to the increasing utilization of MRI. Although an FTL may be associated with tethered cord syndrome (TCS), in many cases FTLs are diagnosed incidentally in patients without any symptoms of TCS. The natural history of FTLs is not well defined.

Methods. The authors searched the clinical and imaging records at a single institution over a 14-year interval to identify patients with FTLs. For patients with an FTL, the clinical records were reviewed for indication for imaging, presenting symptoms, perceived need for surgery, and clinical outcome. A natural history analysis was performed using all patients with more than 6 months of clinical follow-up.

Results. A total of 436 patients with FTL were identified. There were 217 males and 219 females. Of these patients, $282(65 \%)$ were adults and $154(35 \%)$ were children. Symptoms of TCS were present in 22 patients $(5 \%)$. Fifty-two patients underwent surgery for FTL (12\%). Sixty-four patients (15\%) had a low-lying conus and $21(5 \%)$ had a syrinx. The natural history analysis included 249 patients with a mean follow-up time of 3.5 years. In the follow-up period, only 1 patient developed new symptoms.

Conclusions. Filum terminale lipomas are a common incidental finding on spinal MRI, and most patients present without associated symptoms. The untreated natural history is generally benign for asymptomatic patients. (http://thejns.org/doi/abs/10.3171/2014.2.PEDS13528)
\end{abstract}

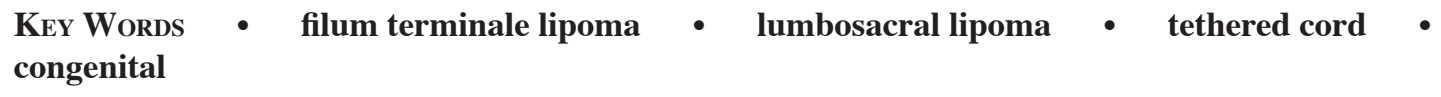

$\mathrm{F}$ ILUM terminale lipomas (FTLs) are a type of lumbosacral lipoma in which the fat is entirely within the filum terminale and separate from the conus medullaris. ${ }^{13}$ Cadaveric studies have demonstrated a prevalence of $4 \%-6 \%{ }^{12}$ in otherwise normal spines, and MRI prevalence estimates have ranged between $0.24 \%$ and $4 \% .1,4,29$ Filum terminale lipomas are occasionally associated with tethered cord syndrome (TCS), and some authors have advocated for prophylactic sectioning of the filum terminale when an FTL is identified. ${ }^{14,16}$ With the increasing use of MRI, FTLs have been identified more frequently in asymptomatic individuals. ${ }^{4,5,29}$ There has been no large study describing the natural history of FTLs or the expected distribution of conus position in patients with FTL compared with individuals without FTL.

Abbreviations used in this paper: $\mathrm{FTL}=$ filum terminale lipoma; TCS $=$ tethered cord syndrome.

\section{Methods}

After obtaining approval from the University of Michigan Institutional Review Board, we reviewed the medical records of all patients evaluated at our institution between January 1, 1997, and December 31, 2011, to identify those patients with clinical or imaging evidence of an FTL. The records of 50,249 consecutive patients who underwent lumbar spinal MRI were searched for the terms "filum" in combination with the terms "fat" or "lipoma" and derivatives of those terms such as "fatty," "fibrofatty," or "lipomatous" using a free text search engine (RadQuery). We manually read and viewed the medical and imaging records of all patients identified in this population using the search engine to confirm the presence of an FTL. Patients were considered to have an FTL if the interpreting neuroradiologist made this diagnosis on the MRI report. Patients were excluded if they had other spinal lipomas including conus lipomas or lipomyelomeningocele. Patients 
with myelomeningocele, dermal sinus tract, diastematomyelia, or sacral agenesis were also excluded.

For patients with FTL, we collected demographic information including age, sex, presenting symptoms, the indication given for the initial MRI study, and, if any surgical treatment was pursued, the surgical data including choice of surgery and treatment outcomes. Magnetic resonance imaging records were reviewed in every case to confirm the diagnosis of an FTL. For the purpose of this analysis, patients were considered to be symptomatic if the evaluating clinician had indicated any concern for symptoms in the medical record. Imaging characteristics were evaluated including verification of FTL, the location of the conus, presence of a syrinx, and presence of vertebral anomalies such as hemivertebrae.

Conus levels were recorded for all patients with adequate imaging records, which included axial imaging through the level of the conus and lumbar vertebrae to the lumbosacral junction. Conus level was assigned based on the adjacent vertebral body or disc space at the level of the inferior termination of the spinal cord. Levels were determined by counting up from the lumbosacral junction. The most caudal modal rectangular lumbar vertebra was considered L-5 for the purposes of this analysis. ${ }^{20}$ Sufficient data were available to use this technique to assess the conus level in 405 of 436 patients. We randomly selected 150 adults without FTLs and a group of 152 age- and sexmatched children without FTLs as control subjects from our database of all patients undergoing lumbar MRI. Conus levels were recorded for this control population of adults and children. For the purpose of this analysis, conus termination below the vertebral body of L-2 was considered low lying.

\section{Natural History Data Collection}

Patients with untreated FTLs who had clinical follow-up of 6 months or longer were evaluated to assess the natural history of the lesions. Patients were assessed for development of new symptoms and changes in existing symptoms, as well as for surgical treatment.

\section{Data Analysis}

Analyses were performed to evaluate the association of age, sex, initial imaging characteristics (level of conus, presence of syrinx, and presence of vertebral anomalies), clinical characteristics of symptoms, surgical intervention, conus level, presence of syrinx, and other imaging characteristics using the Fisher exact test and ANOVA testing. Multivariate logistic regression was performed to assess age, sex, and imaging characteristics and their association with symptoms and surgical intervention. Conus levels were compared in patients with an FTL and in the control population using ordinal regression. Data were analyzed using SPSS (version 20.0, IBM SPSS), and SAS (version 9.3, SAS Institute Inc.).

\section{Results}

\section{Presentation}

We identified 436 patients with FTL of approximately equal sex distribution (217 males and 219 females). There were 282 adults (65\%) and 154 children (35\%). The mean age of all patients was $34.9 \pm 25.3$ years. The most common indication for initial imaging in these patients was back pain with or without neurological complaints (59\%), kyphoscoliosis (13\%), and history of malignancy (11\%). Vertebral anomalies were identified in $11 \%$ of patients, including hemivertebrae (7\%), congenital fusion (2\%), and segmentation abnormalities (2\%).

The conus level could be assessed in 405 of 436 patients, which included 253 adults and 152 chidlren and was found to be low lying in 64 patients (16\%). Low conus position was found more frequently in children with FTL than in adults $(\mathrm{p}<0.001)$. There were 45 children $(30 \%)$ with a low conus position but only 19 adults (8\%) (Tables $1-3$, Figs. 1 and 2). Spinal syrinx was also found more frequently in children $(\mathrm{p}<0.001)$. Twenty-one patients $(5 \%)$ had a syrinx; 3 were in adults and 18 were in children.

Most patients were asymptomatic at presentation $(95 \% ; n=414)$. Twenty-two patients $(5 \%)$ were considered symptomatic at the time of the initial evaluation; 7 of these were adults and 15 were children (Table 4). Younger age was associated with symptomatic presentation $(\mathrm{p}=$ 0.002). In children, all patients with symptoms were 9 years of age or younger. Among symptomatic patients, the most common symptoms were urological abnormalities in $59 \%$, back pain in $32 \%$, and leg pain in $32 \%$. A lower conus level was significantly associated with symptomatic presentation. Of the 22 patients who presented with possible symptoms, $17(77 \%)$ had a low-lying conus $(\mathrm{p}<$ $0.0001)$. Low conus level had a positive predictive value for symptoms of $27 \%$ (17 of 64), but a normal conus level had a negative predictive value for symptoms of $99 \%$ (367 of 372). Presence of a syrinx was not significantly associated with symptomatic presentation. Only $2(9 \%)$ of 22 patients with symptoms had an associated syrinx ( $\mathrm{p}=$ $0.3)$. There was no correlation between sex and symptoms. Twelve males and 10 females had symptoms. After multivariate analysis, only a low-lying conus was significantly associated with symptomatic presentation $(\mathrm{p}<0.0001)$.

Surgery

Fifty-two patients underwent sectioning of the FTL (12\%). Of these patients, 21 presented with symptoms of TCS prior to surgery. Twelve had urological symptoms and 10 underwent urodynamic studies prior to surgery. Twenty-two patients had no symptoms of TCS prior to surgical untethering. Nineteen of these patients had a low-lying cord, a spinal syrinx, or both. Nine otherwise asymptomatic patients underwent surgical untethering at the time of scoliosis repair. The scoliosis in these patients was considered secondary to skeletal abnormalities including hemivertebrae and segmentation abnormalities in every case. Most of those undergoing sectioning were children $(n=45 ; 87 \%)$. Younger patients were more likely to undergo untethering, with a mean age of 8.7 years for patients undergoing surgery versus 38.4 years in untreated patients $(\mathrm{p}<0.0001)$. Patients with a low-lying conus were also more likely to undergo sectioning of the FTL. Thirty-seven patients $(71 \%)$ who underwent surgery had a low-lying conus $(\mathrm{p}<0.001)$. Patients with evidence of a 
Filum terminale lipoma

TABLE 1: Conus level in 282 adult patients with FTL

\begin{tabular}{lccc}
\hline & \multicolumn{3}{c}{ Adult Patients } \\
\cline { 2 - 4 } Conus Level & All Patients & Female & Male \\
\hline T-11 & $0.4 \%$ & $0.0 \%$ & $0.8 \%$ \\
T11-12 & $0.8 \%$ & $1.6 \%$ & $0.0 \%$ \\
T-12 & $7.5 \%$ & $3.2 \%$ & $11.8 \%$ \\
T12-L1 & $16.6 \%$ & $18.3 \%$ & $15.0 \%$ \\
L-1 & $41.9 \%$ & $38.9 \%$ & $44.9 \%$ \\
L1-2 & $13.0 \%$ & $14.3 \%$ & $11.8 \%$ \\
L-2 & $12.3 \%$ & $13.5 \%$ & $11.0 \%$ \\
L2-3 & $2.4 \%$ & $3.2 \%$ & $1.6 \%$ \\
L-3 & $1.6 \%$ & $2.4 \%$ & $0.8 \%$ \\
L3-4 & $1.2 \%$ & $0.8 \%$ & $1.6 \%$ \\
L-4 & $0.8 \%$ & $1.6 \%$ & $0.0 \%$ \\
L4-5 & $0.8 \%$ & $1.6 \%$ & $0.0 \%$ \\
L-5 & $0.4 \%$ & $0.8 \%$ & $0.0 \%$ \\
L5-S1 & $0.4 \%$ & $0.0 \%$ & $0.8 \%$ \\
\hline
\end{tabular}

syrinx were also more likely to undergo surgery. Eleven patients $(21 \%)$ who underwent surgery had a syrinx $(\mathrm{p}<$ $0.001)$. After multivariate analysis, younger patients $(\mathrm{p}<$ $0.0001)$ and patients with a low-lying conus ( $\mathrm{p}<0.0001)$ were more likely to undergo surgical untethering.

Two patients experienced a complication following FTL sectioning. One patient developed a symptomatic pseudomeningocele requiring surgical repair. Another patient developed a seroma that was managed conservatively. Of the 21 patients with symptoms, 9 remained stable postoperatively, while 12 patients had subjective clinical improvement.

\section{Conus Level}

The conus level was examined in 405 patients with available imaging, including 253 adults and 152 children. This level was compared with the conus levels of 150 randomly selected control adults and randomly selected equally age- and sex-matched control pediatric patients (Fig. 1). In adults, the conus level in patients and controls appears to have a normal-type distribution that nearly overlaps, except for a small group of those with FTL and low-lying conus. Despite the similar graphical distribution in adults between those with and without FTL, the group of FTL patients with a low-lying conus accounts for a small but significant difference $(\mathrm{p}=0.004)$ in conus position. In children, there is a clear difference in conus position between the FTL and control groups, with a larger proportion of patients having a lower conus than controls ( $\mathrm{p}<0.0001)$. When children and adults are compared with each other, children with FTL appear to be more likely to have low conus position than adults with FTL. Since symptomatic patients are more likely to have a low conus position (Fig. 2), some of this difference may be accounted for by the larger number of children with symptoms.

\section{Natural History}

The natural history analysis included 249 patients
TABLE 2: Conus levels in 154 children with FTL stratified by age group

\begin{tabular}{lrrrrr}
\hline & \multicolumn{5}{c}{ Age Group } \\
\cline { 2 - 5 } Conus Level & $<1 \mathrm{Yr}$ & $1-5 \mathrm{Yrs}$ & $6-11 \mathrm{Yrs}$ & $12-17 \mathrm{Yrs}$ & All Patients \\
\hline T-11 & $0.0 \%$ & $1.7 \%$ & $0.0 \%$ & $0.0 \%$ & $0.7 \%$ \\
T11-12 & $0.0 \%$ & $0.0 \%$ & $0.0 \%$ & $0.0 \%$ & $0.0 \%$ \\
T-12 & $0.0 \%$ & $0.0 \%$ & $2.1 \%$ & $4.3 \%$ & $1.3 \%$ \\
T12-L1 & $0.0 \%$ & $5.0 \%$ & $16.7 \%$ & $4.3 \%$ & $7.9 \%$ \\
L-1 & $9.7 \%$ & $18.3 \%$ & $27.1 \%$ & $30.4 \%$ & $22.4 \%$ \\
L1-2 & $12.9 \%$ & $20.0 \%$ & $8.3 \%$ & $17.4 \%$ & $15.8 \%$ \\
L-2 & $16.1 \%$ & $26.7 \%$ & $20.8 \%$ & $13.0 \%$ & $22.4 \%$ \\
L2-3 & $16.1 \%$ & $11.7 \%$ & $8.3 \%$ & $4.3 \%$ & $11.2 \%$ \\
L-3 & $9.7 \%$ & $5.0 \%$ & $10.4 \%$ & $8.7 \%$ & $8.6 \%$ \\
L3-4 & $12.9 \%$ & $3.3 \%$ & $0.0 \%$ & $0.0 \%$ & $3.9 \%$ \\
L-4 & $9.7 \%$ & $3.3 \%$ & $0.0 \%$ & $0.0 \%$ & $3.3 \%$ \\
L4-5 & $6.5 \%$ & $1.7 \%$ & $0.0 \%$ & $0.0 \%$ & $2.0 \%$ \\
L-5 & $0.0 \%$ & $0.0 \%$ & $0.0 \%$ & $0.0 \%$ & $0.0 \%$ \\
L5-S1 & $3.2 \%$ & $0.0 \%$ & $0.0 \%$ & $0.0 \%$ & $0.7 \%$ \\
\hline
\end{tabular}

with untreated FTLs and clinical follow-up of 6 months or longer. These patients had a mean, untreated, follow-up time of 3.47 years (range $0.5-16.4$ years). There were 125 males and 124 females; 155 were adults and 94 were children. In this cohort, only one patient developed possible new or worsening symptoms after long-term follow-up. This patient initially presented at 6 months of age with radiographic evidence of a filum lipoma and a conus terminating at L1-2 and no symptoms. After 1.5 years of follow-up, she was found to have mild urinary issues with frequent urinary tract infections. She had a unilateral duplicated ureteral system, which was repaired. Following this surgery, she continued to have frequent urinary tract infections of unclear etiology and she underwent surgical untethering. Preoperative urodynamics were not obtained.

TABLE 3: Conus levels in age-matched children without FTL stratified by age group

\begin{tabular}{|c|c|c|c|c|c|}
\hline \multirow[b]{2}{*}{ Conus Level } & \multicolumn{4}{|c|}{ Age Group } & \multirow[b]{2}{*}{ All Patients } \\
\hline & $<1 \mathrm{Yr}$ & $1-5$ Yrs & $6-11$ Yrs & $12-17$ Yrs & \\
\hline $\mathrm{T}-11$ & $0.0 \%$ & $0.0 \%$ & $0.0 \%$ & $0.0 \%$ & $0.0 \%$ \\
\hline T11-12 & $0.0 \%$ & $0.0 \%$ & $0.0 \%$ & $0.0 \%$ & $0.0 \%$ \\
\hline $\mathrm{T}-12$ & $3.3 \%$ & $5.2 \%$ & $2.2 \%$ & $26.3 \%$ & $6.6 \%$ \\
\hline T12-L1 & $6.7 \%$ & $22.4 \%$ & $24.4 \%$ & $26.3 \%$ & $20.4 \%$ \\
\hline L-1 & $20.0 \%$ & $37.9 \%$ & $51.1 \%$ & $36.8 \%$ & $38.2 \%$ \\
\hline L1-2 & $53.3 \%$ & $22.4 \%$ & $17.8 \%$ & $5.3 \%$ & $25.0 \%$ \\
\hline L-2 & $13.3 \%$ & $10.3 \%$ & $4.4 \%$ & $5.3 \%$ & $8.6 \%$ \\
\hline L2-3 & $0.0 \%$ & $1.7 \%$ & $0.0 \%$ & $0.0 \%$ & $0.7 \%$ \\
\hline L-3 & $3.3 \%$ & $0.0 \%$ & $0.0 \%$ & $0.0 \%$ & $0.7 \%$ \\
\hline L3-4 & $0.0 \%$ & $0.0 \%$ & $0.0 \%$ & $0.0 \%$ & $0.0 \%$ \\
\hline L-4 & $0.0 \%$ & $0.0 \%$ & $0.0 \%$ & $0.0 \%$ & $0.0 \%$ \\
\hline L4-5 & $0.0 \%$ & $0.0 \%$ & $0.0 \%$ & $0.0 \%$ & $0.0 \%$ \\
\hline L-5 & $0.0 \%$ & $0.0 \%$ & $0.0 \%$ & $0.0 \%$ & $0.0 \%$ \\
\hline L5-S1 & $0.0 \%$ & $0.0 \%$ & $0.0 \%$ & $0.0 \%$ & $0.0 \%$ \\
\hline
\end{tabular}


M. J. Cools et al.
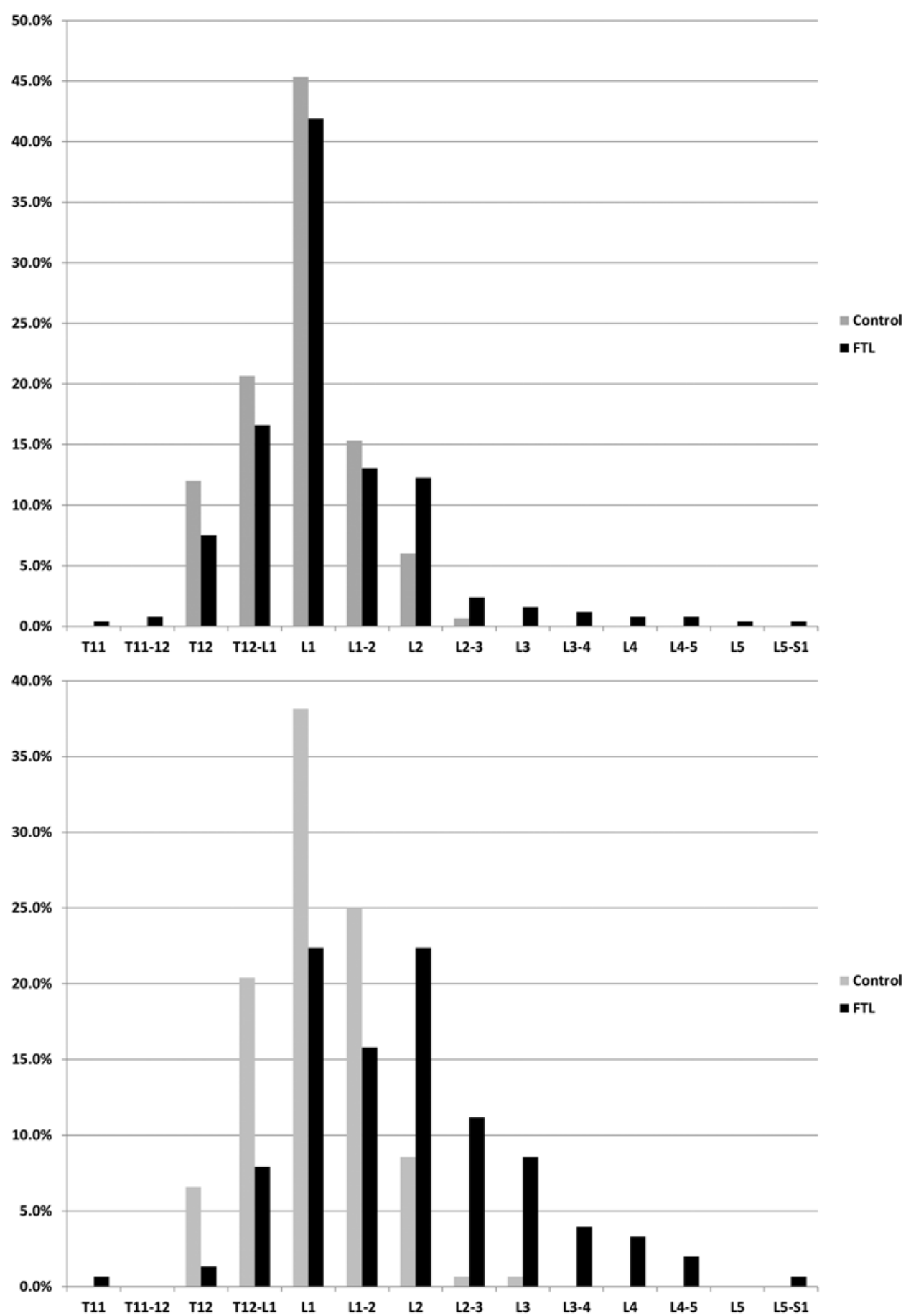

FIG. 1. Upper: Conus level percentages for 2 populations: adult patients with lipomas (FTL) compared with a normal control adult population. Lower: Percentage of patients within each conus level for 2 populations: children with lipomas (FTL) and age- and sex-matched control pediatric patients.

Afterward, her symptoms improved with urodynamic studies showing no evidence of neurogenic bladder. No other patient developed new or worsening symptoms in this follow-up period.

Although only one patient developed possible new symptoms, a total of 15 of 52 patients undergoing surgery were in the natural history group and underwent surgical untethering after an initial decision to undergo conserva- tive management. Of these 15 patients, 14 had no evidence of symptoms. Five patients underwent untethering at the time of scoliosis repair, and 9 had no symptoms of TCS prior to surgical untethering. Of these 9 patients without symptoms, most had a low-lying conus, a syrinx, or both.

In the natural history group, 31 patients had a lowlying conus at the time of initial evaluation. Of these patients, 23 were children and 8 were adults. None of these 


\section{Filum terminale lipoma}

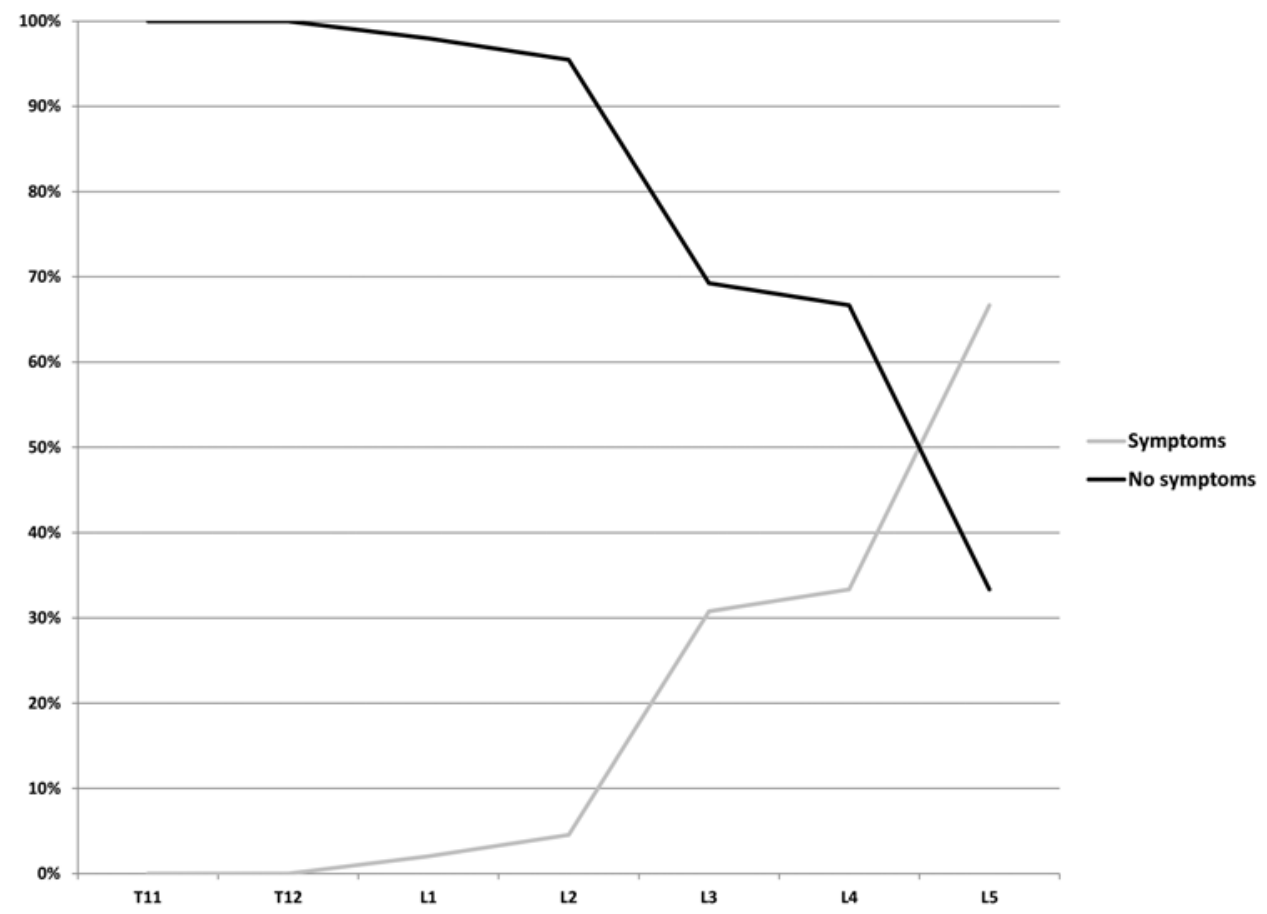

FIG. 2. Graph showing the percentage of patients within each conus level in those presenting with symptoms compared with patients presenting incidentally.

patients developed new or worsening symptoms during follow-up. Of the 31 patients, 9 underwent surgical untethering in the follow-up period, 2 patients underwent untethering at the time of scoliosis repair, and 7 had no symptoms of TCS (as noted above).

\section{Discussion}

With the increasing use of diagnostic imaging, there has been an increase in the identification of FTLs. Though initially thought to be associated with TCS in many or even most cases ${ }^{14}$ the clinical significance of FTL has recently been called into question. . $^{1,529}$ Using search results from a large imaging database, we report on the largest series of FTLs to date. Most patients with FTL seen on MRI had no symptoms (95\%). In the 22 patients with symptoms, the most common were urological complaints $(59 \%)$, back pain (32\%), and leg pain (32\%). The only factor associated with the presence of symptoms was a lower conus level.

Previous studies have analyzed small cohorts of patients undergoing imaging and have suggested that most FTLs identified in adults are incidental findings. $1,4,5,29$ Brown et al. ${ }^{4}$ examined $100 \mathrm{MR}$ images of the spine at their institution and identified 4 FTLs, none of which were symptomatic. Some have attempted to correlate radiographic findings with clinical presentation. Bulsara et al. ${ }^{5}$ evaluated 36 patients with FTLs and concluded that in symptomatic patients, the fat within the filum was closer to the conus than in asymptomatic patients. The level of the conus and thickness of the filum terminale, however, did not correlate with symptomatic cord tethering. It is worth noting that the rate of symptoms attributed to tethering because of the FTL in their study was higher than the rate in our patients ( $42 \%$ vs $2 \%$ ), reflecting different detection methods and a bias toward the discovery of symptomatic lesions in that series. $.^{5} \mathrm{Al}-\mathrm{Omari}$ et al. ${ }^{1} \mathrm{did}$ not find any correlation between filum thickness, length of the lipoma, or distance from the conus with symptomatic presentation. That study identified 37 patients with simple FTLs in a review of 1205 lumbosacral MR images performed at their institution. They found that FTLs identified in adult patients were likely incidental findings and did not require intervention. However, they excluded pediatric patients and any patient who had a conus below L-2 from their study, groups that are more likely to present with symptoms.

We attempted to identify factors associated with symptomatic presentation. We found that although most symptomatic patients had a low-lying conus (17 of 22; $77 \%$ ), most patients with a low-lying conus did not have

TABLE 4: Presenting symptoms in 22 patients with FTL (7 adults and 15 children)*

\begin{tabular}{lc}
\hline \multicolumn{1}{c}{ Symptom } & No. of Cases (\%) \\
\hline urological complaint & $13(59)$ \\
bowel abnormality & $5(23)$ \\
leg pain & $7(32)$ \\
back pain & $7(32)$ \\
motor/gait disturbance & $6(27)$ \\
sensory complaint & $3(14)$ \\
orthopedic abnormality & $2(9)$ \\
\hline
\end{tabular}

* Most patients had more than 1 presenting symptom. 
symptoms (47 of $64 ; 73 \%$ ). A normal conus level was a negative predictor for symptoms. We also sought to determine if the presence of an FTL was associated with a low conus position. In adults, the conus level in patients with FTL and controls was very similar, with the most common termination of the conus at the L-1 level, consistent with previous studies of normal conus levels. ${ }^{8,23}$ However, a sufficient number of adults exhibited a low conus position in the FTL group to produce a statistical, if not impressive, visual difference from the adult control group (Fig. 1). In children, there is a more obvious visual and statistical skewing of the distribution toward a lower conus level in patients with FTLs compared with age- and sex-matched controls. We found that many of the patients with a lower conus level were those who presented with symptoms.

Comparing adult and pediatric patients with FTLs, there is a higher percentage of children with a low conus position. There are several possible explanations for this difference. First, it is likely that at least some of this difference may be due to the greater likelihood of symptomatic presentation during childhood and the greater percentage of symptomatic children in this study compared with adults. Symptoms are associated with low conus position. It is also possible, since the adults and children undergo imaging for different reasons, that the adult cohort is fundamentally different from the pediatric cohort rather than merely older examples of a similar population. Although we believe that this selection bias must be considered in any analysis of our results, it is mitigated to some extent by the asymptomatic nature of most patients with a fatty filum and the large number of patients studied. Finally, it is possible that our finding of a lower conus position in children is a real phenomenon and that children with FTL have a lower conus position that persists later than in controls, even in asymptomatic individuals. In individuals without an FTL, the conus position is not expected to ascend to any significant degree beyond infancy. ${ }^{9,15,31,32}$ In contrast to this, we found that those with an FTL had a higher conus position with advancing age later in childhood (Fig. 3). This finding lends support to the notion that the lower conus position in childhood is a real phenomenon for those with FTL, even in asymptomatic individuals.

This is the only study evaluating the untreated natural history of FTLs. We identified 249 patients with FTL with a mean follow-up time of 3.5 years. Of these patients, only 1 developed new or worsening symptoms during the follow-up period. This was a child with a normal conus level who was diagnosed at 6 months of age with an asymptomatic lesion and developed mild urinary issues of unclear etiology after 1.5 years of follow-up. No adults developed new or worsening symptoms after long-term follow-up. Overall, 33 patients who had a low-lying conus at initial presentation underwent follow-up, and none developed new or worsening symptoms. Given the increasing rate of surgical complications reported and the increasing rate of retethering identified, the natural history of asymptomatic FTLs may be superior to outcomes following surgery. We found that children were more likely to present with symptoms than adults, and that within the pediatric age group, younger children were more likely to present with symptoms than older children. This must be taken into account in any interpretation of the natural history data. Since the natural history analysis included patients of all ages, one must consider the possibility that the natural history could be worse in children, particularly young children, compared with a group composed of patients of all ages.

Symptoms of TCS include back and lower-extremity pain, urological abnormalities, lower-extremity weakness, and deformities such as pes cavus. ${ }^{14,17,22,33}$ Although a lowlying conus has been considered an important finding in most patients with TCS, several groups have suggested that symptoms of TCS may exist with a normal conus medullaris position. ${ }^{25,28,30}$ Others have pointed out that symptoms such as back pain and urological complaints are common in children without neurological abnormalities and that many of these symptoms resolve with time, medical management, and behavioral therapy. ${ }^{10,11}$ Therefore, the management of children with subjective symptoms of TCS in the setting of a normal conus level is controversial..$^{10,11}$ Interestingly, a study examining practice patterns found that neurosurgeons were much more likely to diagnose TCS in the setting of a normal conus position if patients had an FTL. ${ }^{27}$ In our series, 5 patients with FTLs had possible TCS symptoms with a normally positioned conus.

Many groups have recommended prophylactic treatment for asymptomatic patients with FTL, especially if the conus is low lying. ${ }^{3,16,22,25}$ La Marca, et al. ${ }^{16}$ described 55 patients with FTLs, $51 \%$ of whom were asymptomatic, and compared operative outcomes of asymptomatic patients and symptomatic patients. They found that $96 \%$ of symptomatic patients improved or remained stable, while all patients who were asymptomatic remained asymptomatic. Pierre-Kahn et al. ${ }^{22}$ described 38 patients with FTLs, 55\% of whom were asymptomatic, who underwent an untethering procedure. During the 1-year postoperative follow-up period, no asymptomatic patient had developed symptoms, and all patients who were symptomatic had either improved $(53 \%)$ or stabilized $(47 \%)$. There were 10 patients who had 5 years of follow-up, of whom 7 were asymptomatic prior to surgery. One of the patients who was asymptomatic preoperatively developed symptoms, while all others remained asymptomatic. ${ }^{22}$ A recent case series of FTL sectioning identified complication rates as high as $12 \%$, including wound infections, CSF leaks,

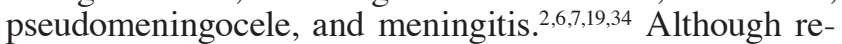
tethering following sectioning of an FTL was considered rare in the past, ${ }^{6,16}$ recent series with longer follow-up periods have found retethering rates between $2.7 \%$ and $8.6 \%$. Retethering occurs both in symptomatic patients and in those who underwent prophylactic sectioning of the filum. $7,18,19,24,26,34$

While these studies address the outcomes for asymptomatic patients undergoing surgical untethering, they do not address the natural history for asymptomatic patients with FTLs who do not undergo surgical untethering. We believe that the natural history of an FTL, as well as its prevalence in those undergoing imaging, does not justify prophylactic surgery in most asymptomatic cases. Prophylactic surgery may have a role in certain exceptional cases, 
A

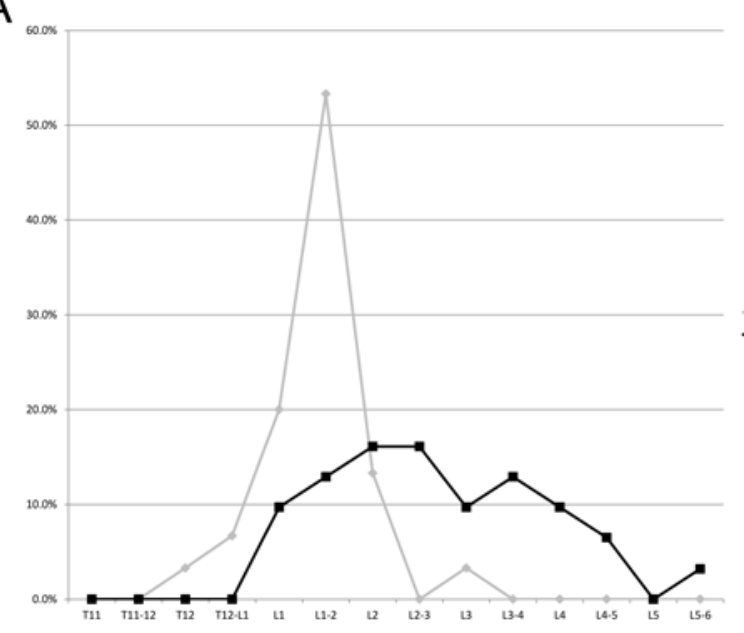

C

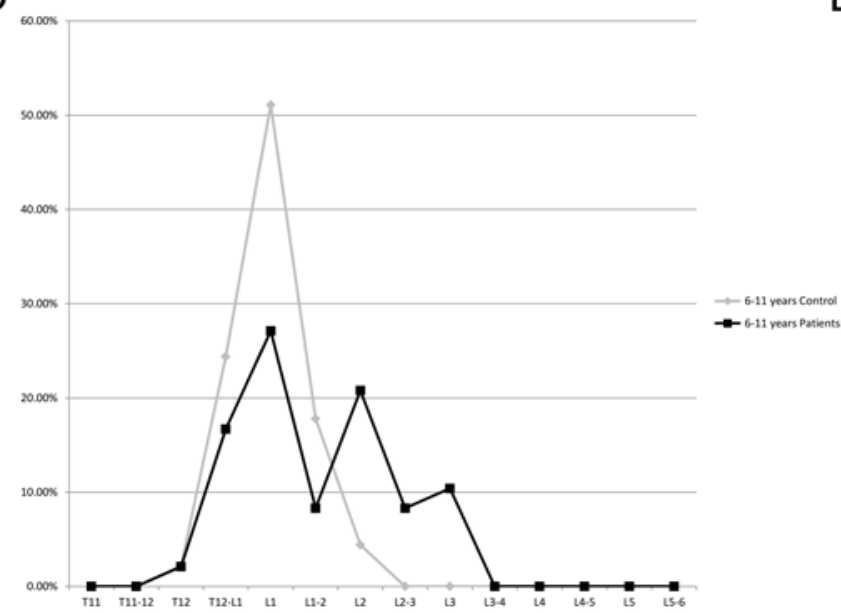

B

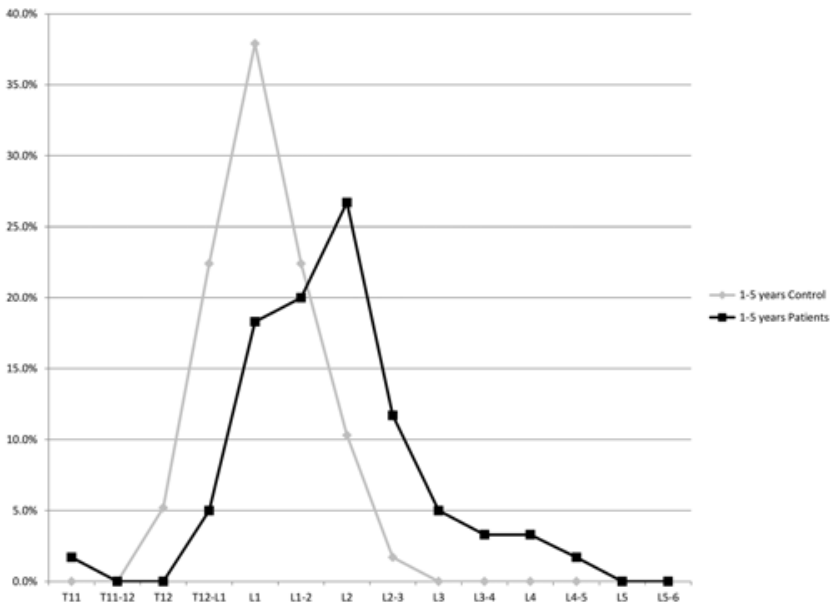

D

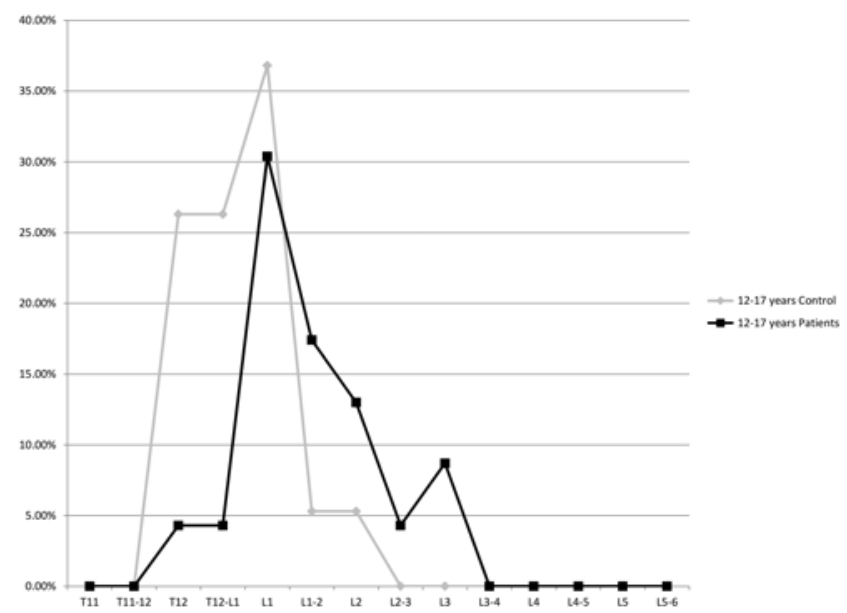

FIG. 3. Conus position in children with FTL and controls without FTL stratified by age group: younger than 1 year (A), (B) 1-5 years (B), 6-11 years (C), and 12-17 years (D). Individuals in the FTL group demonstrate a higher conus position with advancing age during childhood. As expected, the control group does not demonstrate the increase after infancy.

such as for patients undergoing a significant scoliosis correction with the potential for spinal cord traction.

This study is limited by several factors. This is a retrospective review of radiological and neurosurgical databases. There is a selection bias, as FTLs are likely underreported on MRI reports since many radiologists consider them to be incidental. ${ }^{5}$ Therefore, prevalence cannot be calculated based on this study. Similarly, the assessment of symptoms was drawn from the medical records. Clinicians making this assessment most likely had knowledge of the MRI results, introducing a potential diagnostic suspicion bias.

We included patients in this analysis if they had findings that met the definition of a fatty filum, that is, if any part of the filum terminale exhibited thickening with fat signal on MRI ( $>2 \mathrm{~mm}$ thick and bright on T1-weighted MRI). We did not attempt to differentiate patients on the basis of length of the fatty filum or level of the fatty segment below the conus. Patients were included even if they had never been referred for neurosurgical evaluation. It is possible that patients who have been referred for neurosurgical evaluation are more likely to present with symptoms.
In children, a large number of patients underwent surgical untethering without clear symptoms. It should not be concluded that all of these children benefitted from prophylactic surgery or even that surgical treatment was indicated in many of these children. The group of patients evaluated in the natural history analysis was selected for nonsurgical management. Therefore, this analysis should only apply to the group of patients with FTLs who are managed nonoperatively. Any conclusions that may be derived from these asymptomatic or minimally symptomatic patients should not be applied to symptomatic patients who are ordinarily considered good surgical candidates. It is likely that the natural history is worse for more symptomatic patients, for whom surgery is usually offered. Furthermore, our mean natural history follow-up period may be insufficient to capture all cases of clinical deterioration that could be seen over longer follow-up periods, an especially relevant consideration when evaluating a young child prior to his or her expected period of greatest longitudinal growth. In some cases, patients were initially recommended for nonsurgical management and then later underwent surgical untethering despite a lack of any new symptoms or 
radiological findings. In these cases, the decision to offer surgery was made because of continued family and physician concern despite a lack of clinical worsening. Patients with more complex intradural causes of tethering, such as a history of myelomeningoceles, lipomyelomeningoceles, conus lipomas, diastematomyelia, dermal sinus tracts, or complete sacral agenesis, were excluded. Our conclusions should not be applied to patients with these other conditions.

Finally, it is worth noting that no method for counting vertebral levels in the lumbar spine on MRI is perfectly accurate. ${ }^{20,21}$ We used the commonly accepted technique of labeling the most caudal of the rectangular-type vertebrae as the fifth lumbar level.9,20,31,32 This technique does not readily take into account those with more than or fewer than 5 lumbar vertebrae. In a recent analysis of 8280 patients undergoing MRI, Paik et al..$^{20}$ found that the last rectangular-type lumbar vertebra with a modal L-5 appearance represented L-4 or L-6 in $2.6 \%$ and $2.9 \%$ of patients, respectively. Review of MRI of the entire spine, not just the lumbar spine, would provide a basis for a more accurate assessment in these cases. Nevertheless, in our analysis, since levels were counted in the same manner for both the case and control groups, no difference between groups should be expected based on our method of counting levels.

\section{Conclusions}

Filum terminale lipomas are increasingly being identified on imaging. Most patients are asymptomatic., ${ }^{1,45}$ Our data demonstrate that the natural history of asymptomatic FTLs is generally benign. Asymptomatic adults do not require frequent follow-up or surgical intervention. Asymptomatic children with a low conus position should be monitored closely, but prophylactic surgery confers no benefit in most cases. Clearly, symptomatic patients should be treated with surgical untethering.

\section{Acknowledgments}

We would like to thank Kathleen Welch for her assistance with statistical analysis and Holly Wagner for providing editorial assistance.

\section{Disclosure}

The authors report no conflict of interest concerning the materials or methods used in this study or the findings specified in this paper. Dr. La Marca reports that he is a consultant for Globus and Biomet and receives support for non-study-related clinical or research effort from Globus.

Author contributions to the study and manuscript preparation include the following. Conception and design: Maher, Al-Holou. Acquisition of data: Cools, Al-Holou, Stetler, Wilson. Analysis and interpretation of data: Al-Holou, Maher, Ibrahim, Muraszko, Garton, Cools. Drafting the article: Cools, Maher, Garton, Muraszko, AlHolou. Critically revising the article: all authors. Reviewed submitted version of manuscript: all authors. Approved the final version of the manuscript on behalf of all authors: Maher, Al-Holou. Study supervision: Maher.

\section{References}

1. Al-Omari MH, Eloqayli HM, Qudseih HM, Al-Shinag MK:
Isolated lipoma of filum terminale in adults: MRI findings and clinical correlation. J Med Imaging Radiat Oncol 55:286290, 2011

2. Arai H, Sato K, Okuda O, Miyajima M, Hishii M, Nakanishi $\mathrm{H}$, et al: Surgical experience of 120 patients with lumbosacral lipomas. Acta Neurochir (Wien) 143:857-864, 2001

3. Blount JP, Elton S: Spinal lipomas. Neurosurg Focus 10(1):E3, 2001

4. Brown E, Matthes JC, Bazan C III, Jinkins JR: Prevalence of incidental intraspinal lipoma of the lumbosacral spine as determined by MRI. Spine (Phila Pa 1976) 19:833-836, 1994

5. Bulsara KR, Zomorodi AR, Enterline DS, George TM: The value of magnetic resonance imaging in the evaluation of fatty filum terminale. Neurosurgery 54:375-380, 2004

6. Bulsara KR, Zomorodi AR, Villavicencio AT, Fuchs H, George TM: Clinical outcome differences for lipomyelomeningoceles, intraspinal lipomas, and lipomas of the filum terminale. Neurosurg Rev 24:192-194, 2001

7. Cornips EM, Vereijken IM, Beuls EA, Weber JW, Soudant DL, van Rhijn LW, et al: Clinical characteristics and surgical outcome in 25 cases of childhood tight filum syndrome. Eur $\mathbf{J}$ Paediatr Neurol 16:103-117, 2012

8. Demiryürek D, Aydingöz U, Akşit MD, Yener N, Geyik PO: MR imaging determination of the normal level of conus medullaris. Clin Imaging 26:375-377, 2002

9. DiPietro MA: The conus medullaris: normal US findings throughout childhood. Radiology 188:149-153, 1993

10. Drake JM: Occult tethered cord syndrome: not an indication for surgery. J Neurosurg 104 (5 Suppl):305-308, 2006

11. Drake JM: Surgical management of the tethered spinal cordwalking the fine line. Neurosurg Focus 23(2):E4, 2007

12. Emery JL, Lendon RG: Lipomas of the cauda equina and other fatty tumours related to neurospinal dysraphism. Dev Med Child Neurol Suppl 20:62-70, 1969

13. Finn MA, Walker ML: Spinal lipomas: clinical spectrum, embryology, and treatment. Neurosurg Focus 23(2):E10, 2007

14. Hoffman HJ, Hendrick EB, Humphreys RP: The tethered spinal cord: its protean manifestations, diagnosis and surgical correction. Childs Brain 2:145-155, 1976

15. Kesler H, Dias MS, Kalapos P: Termination of the normal conus medullaris in children: a whole-spine magnetic resonance imaging study. Neurosurg Focus 23(2):E7, 2007

16. La Marca F, Grant JA, Tomita T, McLone DG: Spinal lipomas in children: outcome of 270 procedures. Pediatr Neurosurg 26:8-16, 1997

17. Metcalfe PD, Luerssen TG, King SJ, Kaefer M, Meldrum KK, Cain MP, et al: Treatment of the occult tethered spinal cord for neuropathic bladder: results of sectioning the filum terminale. J Urol 176:1826-1830, 2006

18. Ogiwara H, Lyszczarz A, Alden TD, Bowman RM, McLone DG, Tomita T: Retethering of transected fatty filum terminales. Clinical article. J Neurosurg Pediatr 7:42-46, 2011

19. Ostling LR, Bierbrauer KS, Kuntz C IV: Outcome, reoperation, and complications in 99 consecutive children operated for tight or fatty filum. World Neurosurg 77:187-191, 2012

20. Paik NC, Lim CS, Jang HS: Numeric and morphological verification of lumbosacral segments in 8280 consecutive patients. Spine (Phila Pa 1976) 38:E573-E578, 2013

21. Peh WC, Siu TH, Chan JH: Determining the lumbar vertebral segments on magnetic resonance imaging. Spine (Phila Pa 1976) 24:1852-1855, 1976

22. Pierre-Kahn A, Zerah M, Renier D, Cinalli G, Sainte-Rose C, Lellouch-Tubiana A, et al: Congenital lumbosacral lipomas. Childs Nerv Syst 13:298-335, 1997

23. Saifuddin A, Burnett SJ, White J: The variation of position of the conus medullaris in an adult population. A magnetic resonance imaging study. Spine (Phila Pa 1976) 23:1452-1456, 1998

24. Samuels R, McGirt MJ, Attenello FJ, Garcés Ambrossi GL, 


\section{Filum terminale lipoma}

Singh N, Solakoglu C, et al: Incidence of symptomatic retethering after surgical management of pediatric tethered cord syndrome with or without duraplasty. Childs Nerv Syst 25: 1085-1089, 2009

25. Selden NR: Occult tethered cord syndrome: the case for surgery. J Neurosurg 104 (5 Suppl):302-304, 2006

26. Souweidane MM, Drake JM: Retethering of sectioned fibrolipomatous filum terminales: report of two cases. Neurosurgery 42:1390-1393, 1998

27. Steinbok P, Garton HJ, Gupta N: Occult tethered cord syndrome: a survey of practice patterns. J Neurosurg 104 (5 Suppl):309-313, 2006

28. Steinbok P, Kariyattil R, MacNeily AE: Comparison of section of filum terminale and non-neurosurgical management for urinary incontinence in patients with normal conus position and possible occult tethered cord syndrome. Neurosurgery 61:550-556, 2007

29. Uchino A, Mori T, Ohno M: Thickened fatty filum terminale: MR imaging. Neuroradiology 33:331-333, 1991

30. Warder DE, Oakes WJ: Tethered cord syndrome and the conus in a normal position. Neurosurgery 33:374-378, 1993

31. Wilson DA, Prince JR: John Caffey award. MR imaging de- termination of the location of the normal conus medullaris throughout childhood. AJR Am J Roentgenol 152:10291032,1989

32. Wolf S, Schneble F, Tröger J: The conus medullaris: time of ascendence to normal level. Pediatr Radiol 22:590-592, 1992

33. Yamada S, Won DJ, Pezeshkpour G, Yamada BS, Yamada SM, Siddiqi J, et al: Pathophysiology of tethered cord syndrome and similar complex disorders. Neurosurg Focus 23(2):E6, 2007

34. Yong RL, Habrock-Bach T, Vaughan M, Kestle JR, Steinbok P: Symptomatic retethering of the spinal cord after section of a tight filum terminale. Neurosurgery 68:1594-1602, 2011

Manuscript submitted October 8, 2013.

Accepted February 10, 2014.

Please include this information when citing this paper: published online March 14, 2014; DOI: 10.3171/2014.2.PEDS13528.

Address correspondence to: Cormac O. Maher, M.D., Department of Neurosurgery, University of Michigan, 1500 E. Medical Center Dr., Rm. 3552 Taubman Center, Ann Arbor, MI 48109. email: cmaher@med.umich.edu. 